\title{
A test for dominance of cues in the spectacled caiman
}

Caimans were trained to escape shock in a $\mathrm{T}$ maze with confounded visual and spatial cues. Seven of the eight $S s$ quickly reached criterion and were given a single test trial with the positions of the visual cues reversed. When faced with these contradictory cues, all seven turned to the side to which they had been trained.

In his comparative studies of probability matching and habit reversal learning, Bitterman (1965) has stressed the fact that the results often differ when visual discriminations are used rather than spatial discriminations. For example, turtles and decorticate rats showed progressive improvement across reversals with a spatial task, but they did not improve on successive reversals when they were given a series of visual discrimination reversals. However, a recent study (Holmes \& Bitterman, 1966) indicated that turtles could improve on successive visual reversals if certain procedural changes were made. In an article on selective attention during discrimination learning, Mackintosh (1965) has shown that overtraining in rats on a visual discrimination reversal generally facilitates reversal learning, but that overtraining on a spatial reversal generally has no effect (and may either facilitate or retard reversal if an effect is present). This difference is presumably because rats normally attend to spatial cues.

Knowledge concerning the dominant cues in various types of animals should help greatly in interpreting the results of comparative studies, but this information is usually not given. Training Ss on a confounded problem with both visual and spatial cues relevant, and then giving them a test trial with contradictory visual and spatial cues would answer questions as to what cues are dominant in a certain animal (at least in a certain situation). In the present experiment, caimans were trained on a shock escape problem with confounded spatial and visual cues.

Subjects and Housing. Eight spectacled caimans (Caiman sclerops) purchased commercially and about 18 in. in length served as Ss. They were housed in a $2 \times 4 \mathrm{ft}$ tank in which water temperature was maintained at about $90^{\circ}$ F. Each morning the water was changed and a sun lamp was turned on for about $9 \mathrm{~h}$. The diet consisted of ground chicken parts (including bones) with cod liver oil added periodically. Identification of individual Ss was made possible by the use of varicolored neckbands.

Apparatus. The apparatus was a modified $\mathrm{T}$ maze with galvanized metal sides and a floor made of 1 in. wide stainless steel plates running diagonally and spaced $1 / 8$ in. apart. The stem and arms of the $T$ were about 5-1/2 in. wide, and the arms made a $90^{\circ}$ turn before the goal box (or cul de sac) so that the goal box was not visible from the choice point. The goal box was a specially built pan which was 18 in. long and held about 7 in. of water. A metal guillotine door converted the incorrect arm into a cul de sac. The wall of the arms opposite the stem was made either black on the left and white on the right, or vice versa, by the use of interchangeable sheet metal panels. A variable voltage transformer delivered a shock through a scrambler to the floor and sides of the maze. A short circuit current of 6 to 8 milliamps was used, depending upon the behavioral reactions of the individual $\mathrm{S}$.

Procedure. On each trial, the $\mathrm{S}$ was removed from the home tank by hand and dropped onto the start area of the grid facing the choice point. When a $S$ entered the goal pan, it was lifted to the home tank, and the $S$ was allowed to swim out. This prevented handling (which was obviously noxious) in the goal area. The goal pan was then refilled with water from the home tank for the next trial. An intertrial interval of 15 min was used to prevent cumulative effects of shock. An error was defined as an entrance into the wrong arm as far as the S's hind legs, and the criterion for learning used was eight consecutive correct trials. Four Ss were trained with right and white positive, and four were trained to go to black on the left. After a $S$ reached criterion, it received a single test trial with the positions of the black and white reversed (and a goal pan at each arm of the $T$ ).

Results and Discussion. Of the eight $\mathrm{Ss}$, seven reached criterion in $8,9,10,10,11,12$, and 16 trials, and the eighth was discarded when it had shown no indications of learning after 30 training trials. On the test trial, all seven Ss made a turn to the side to which they had been trained. Even if the eighth $S$ had made a choice on the basis of brightness, the results would have been significant $(p<.05)$ in favor of spatial cues. Thus, the belief that spatial cues are dominant to visual cues in reptiles was supported.

Incidentally, three Ss were then trained on a visual discrimination with their positive color unchanged and with position cues irrelevant. Two of these learned in 51 and 57 trials, and the third showed some indications of learning by the end of 60 trials. However, two of the Ss took over 40 trials to abandon an almost absolute position preference based upon the positive position in the previous confounded problem.

\section{References}

Bitterman, M. E. Toward a comparative psychology of learning. Amer. Psychologist, 1960, 15, 704-712.

Holmes, P. A., \& Bitterman, M. E. Spatial and vi sual habit reversal in the turtle. J. comp. physiol. Psychol., 1966, 62, 328-331. Mackintosh, N. J. Selective attention in animal discrimination learning. Psychol. Bull., 1965, 64, 124-150. 